\title{
Chiroptical Detection of a Model Ruthenium Dye in Water by Circularly Polarized-Electrochemiluminescence
}

Received 00th January 20xx, Accepted 00th January 20xx DOI: $10.1039 / \times 0 \times x 00000 x$

\author{
Silvia Voci, ${ }^{\text {ta }}$ Francesco Zinna, ${ }^{\text {tb,c }}$ Lorenzo Arrico, ${ }^{\mathrm{b}}$ Stéphane Grass, ${ }^{\mathrm{c}}$ Laurent Bouffier, ${ }^{\mathrm{a}}$ Jérôme \\ Lacour, ${ }^{* c}$ Lorenzo Di Bari*b and Neso Sojic*a
}

We demonstrate the possibility to detect selectively the two enantiomers of a model $\left[\mathrm{Ru}(\mathrm{bpy})_{3}\right]^{2+}$-based dye by circularly polarized-electrochemiluminescence (CP-ECL). This new nature of the ECL emission combines the chiral information intrinsic of CPL methods with an electrogeneration of the excited state. Thus, it opens the possibility to perform ECL-based bioassays or microscopy with efficient chiral dyes.

Electrochemiluminescence (ECL) is the light emission triggered by an initial electrochemical step. ${ }^{1,2}$ It belongs to the general class of chemiluminescence processes involving highly exergonic electron-transfer reactions. This powerful analytical technique is applied in several fields ranging from medical diagnostics, environmental chemistry to food safety analysis. . $^{3}$ The model and most widely used ECL system employed for analytical and imaging purposes consists of the luminophore label $\left[\mathrm{Ru}(\mathrm{bpy})_{3}\right]^{2+}$ (bpy $=2,2^{\prime}$-bipyridine) or one of its derivatives, with tri- $n$-propylamine (TPrA) as a coreactant. ${ }^{5-7}$ Functional forms of this dye bearing reactive groups such as activated esters, for example $\left[\mathrm{Ru}(\mathrm{bpy})_{3}\right]^{2+}-\mathrm{N}$ hydroxysuccinimide ester, are extensively applied to label various biomolecules (e.g., proteins, peptides, ligands and oligonucleotides) for DNA and immunological assays. ${ }^{8,} 9$ Owing to its high sensitivity, remarkable efficiency, labeling versatility for biomolecules, redox stability in oxidation, minimal disturbance to immune recognition, and physiological operating conditions in presence of dissolved dioxygen and potential impurities, $\left[\mathrm{Ru}(\mathrm{bpy})_{3}\right]^{2+}$ and its derivatives are the gold standard dye in ECL. ${ }^{1,2}$

\footnotetext{
a. Univ. Bordeaux, Bordeaux INP, CNRS, Institut des Sciences Moléculaires, UMR 5255.33607 Pessac, France.E-mail:neso.sojic@enscbp.fr.

b. Dipartimento di Chimica e Chimica Industriale. University of Pisa. via G. Moruzzi 13, 56124, Pisa, Italy. E-mail: lorenzo.dibari@unipi.it.

Department of Organic Chemistry. University of Geneva. Quai Ernest Ansermet 30, 1211 Geneva 4, Switzerland. E-mail: Jerome.lacour@unige.ch.

† These authors equally contributed.

Electronic Supplementary Information (ESI) available: [details of any supplementary information available should be included here]. See DOI: 10.1039/x0xx00000x
}

Since ECL is based on an optical readout, light intensity is the signal that is usually measured for analytical and microscopy purposes. Tuning the wavelength of the emission has been widely explored with heteroleptic iridium complexes and various organic dyes. ${ }^{10,11}$ However, when dealing with chiral environments, the ECL features (light intensity, wavelength, Faradaic current) of a couple of enantiomer luminophores are strictly identical. Therefore, measuring these properties of $\mathrm{ECL}$ emission does not allow one to discriminate between them. In other words, classic ECL is insensitive to the enantiomeric nature of a chiral emitter or more in general to the stereochemical information available in a chiral environment, such as biological media.

On the other hand, circular polarization of emitted light contains valuable information about the chirality of the emitter itself or about its interaction with chiral environments. ${ }^{12}$ Indeed, circularly polarized photoluminescence (CP-PL or CPL) has been measured also in case of racemic or non-chiral emitters following and demonstrating their interaction with biomolecular non-racemic analytes. ${ }^{13-15}$ Thus, resolving the circular polarization provides valuable information on optically active chiral molecules. CP-PL or CPL is the differential photoexcited emission of left- or right-circularly polarized emission from an excited electronic state in the presence of a chiral field. In fact, CP-PL is the emission analogue of circular dichroism, in which absorption is considered. The dissymmetry factor $g_{P L}$ allows one to quantify CP-PL: it is defined as $2\left(I_{L}-I_{R}\right) /\left(I_{L}+I_{R}\right)$, where $I_{L}$ and $I_{R}$ are the intensities of the left and right circularly polarized components of the emitted light. $g_{P L}$ values relatively close to the theoretical maximum $\left(\left|10^{-1}\right|-|1|\right)$ are usually reported for chiral lanthanide complexes ${ }^{16}$ and, more rarely, for $\mathrm{Cr}$ compounds, ${ }^{17,18}$ while significantly lower values $\left(\left|10^{-4}\right|-\right.$ $\left.\left|10^{-3}\right|\right)$ are usually measured for other $d$-metal coordination compounds ( $\mathrm{Ru}, \mathrm{Ir}$, etc.) or non-aggregated organic molecules. ${ }^{19}$ Recently, we investigated the circular polarization of the $\mathrm{ECL}$ emission. ${ }^{20}$ We reported the circularly polarized-ECL (CP-ECL) in acetonitrile of a bis-pyrene scaffold mounted on a constrained polyether macrocycle. ${ }^{20} \mathrm{An} E C L$ dissymmetry factor $g_{E C L}$ of ca. 
$\left|8 \times 10^{-3}\right|$ was measured for both enantiomers using benzoyl peroxide coreactant at very negative potentials, which are only accessible in organic solvents. Previously, Blok et al. measured the $g_{E C L}$ value in acidic buffered solution ( $\mathrm{pH} 4.8$ ) of only one enantiomer of the tris-1,10-phenanthroline ruthenium complex, namely the $(+)-\left[\mathrm{Ru}(\text { phen })_{3}\right]^{2+}$ enantiomer. ${ }^{21}$

Herein, we set out to prove without ambiguity the enantiospecific detection of the two enantiomers of a derivative of the model $\left[\mathrm{Ru}(\mathrm{bpy})_{3}\right]^{2+}$ dye by CP-ECL. For that, we investigated the CP-PL and $\mathrm{CP}-\mathrm{ECL}$ characteristics of both enantiomers $\Delta$ - and $\Lambda$-[Ru(dmbpy $\left.)_{3}\right]^{2+}$ with dmbpy $=4,4^{\prime}-$ dimethyl-2,2'-bipyridine (Fig. 1a). The chirality of such octahedral ruthenium complexes made of three bidentate ligands surrounding the central metal ion has attracted a considerable amount of attention for several decades. ${ }^{22-25} D_{3^{-}}$ symmetric derivatives of this type present right- and lefthanded configurations due to the three-bladed propeller arrangement of the ligands referred traditionally as $\Delta$ (or $P$ ) and $\Lambda$ (or $M$ ), respectively (Fig. 1a). The $\left[R u(d m b p y)_{3}\right]^{2+}$ complex was obtained in single enantiomeric form using a chiral anion mediated approach. ${ }^{26}$ In fact, lipophilic hexacoordinated phosphorus(V) TRISPHAT anions, developed in the Lacour's group and abbreviated hereby $\mathrm{TT}^{27}$ can be used as effective resolving agents for cationic $D_{3}$-symmetric coordination complexes. ${ }^{26}$ Thanks to their remarkable lipophilicity, the $P(V)$ anions help the asymmetric partition of metal tris(bipyridyl) derivatives between aqueous and organic phases, ${ }^{28}$ or they induce the facile separation of the corresponding diastereomeric salts by chromatography over silica gel using solvents like $\mathrm{CH}_{2} \mathrm{Cl}_{2}$ as eluent. ${ }^{29}$ The efficacy of the enantiomeric separations depend on the efficiency of the chiral recognition between the two kinds of three-bladed propellers. Experimentally, it was shown that alkyl groups added at the $4,4^{\prime}$-positions of bpy ligands increases quite dramatically stereoselective recognition phenomena along the $C_{3}$-axis of the ruthenium complexes and hence the choice of the dmbpy ligand to improve the resolution. ${ }^{30}$ Practically, we used a recent protocol for the preparation of enantiomeric $[\Delta$ $\left.\mathrm{Ru}(\mathrm{dmbpy})_{3}\right]\left(\mathrm{PF}_{6}\right)_{2}$ and $\left[\Lambda-\mathrm{Ru}(\mathrm{dmbpy})_{3}\right]\left(\mathrm{PF}_{6}\right)_{2}$ (ee $\left.>96 \%\right)$ from salts $\left[\Delta-\mathrm{Ru}(\mathrm{dmbpy})_{3}\right][\Delta-\mathrm{TT}]_{2}$ and $\left[\Lambda-\mathrm{Ru}(\mathrm{dmbpy})_{3}\right][\Delta-\mathrm{TT}]_{2} \cdot{ }^{31}$ Then, an anion metathesis approach was pursued for preparing the targeted water-soluble salts. The exchange of hexafluorophosphate into chloride anions was realized by dissolution of the $\left[\mathrm{Ru}(\mathrm{dmbpy})_{3}\right]\left(\mathrm{PF}_{6}\right)_{2}$ salts in minimum amounts of acetone followed by a dropwise addition a saturated solution of $\left[\mathrm{Bu}_{4} \mathrm{~N}\right] \mathrm{Cl}$ in acetone until precipitation of the desired $\Delta$ and $\Lambda$ $\left[\mathrm{Ru}(\mathrm{dmbpy})_{3}\right] \mathrm{Cl}_{2}$ ion pairs (yields $\left.89-99 \%\right){ }^{\ddagger}$ The absolute configuration of the isolated salts was verified by circular dichroism (ECD, Fig. S1). ${ }^{32,33}$

With the samples in hand, the electrochemical, photophysical and $\mathrm{ECL}$ properties of the enantiopure $\Delta$ - and $\Lambda$-[Ru(dmbpy $\left.)_{3}\right]^{2+}$ complexes were investigated and compared with that racemic $\left[\mathrm{Ru}(\mathrm{bpy})_{3}\right]^{2+}$ standard. As shown in Fig. S2, the voltammograms recorded in PBS exhibit a reversible oxidation wave at the same potential of $E_{o x}=0.89 \mathrm{~V}$ vs. $\mathrm{Ag} / \mathrm{AgCl}$ for both enantiomers. As expected, both behave identically from an electrochemical point of view and are indistinguishable using cyclic voltammetry. However, their oxidation potential is shifted to a lower value in comparison to racemic $\left[\mathrm{Ru}(\mathrm{bpy})_{3}\right]^{2+}\left(E_{o x}=1.07 \mathrm{~V}\right)$ due to the presence of the methyl groups. ${ }^{34,35}$ Both $\Delta$ - and $\Lambda$ -

a)

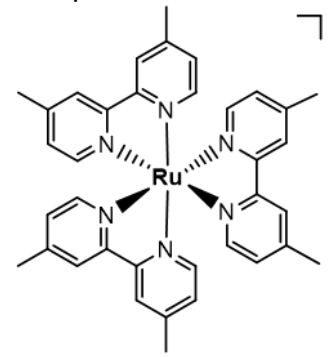

$\Lambda$-[Ru(dmbpy) $\left.)_{3}\right]^{2+}$
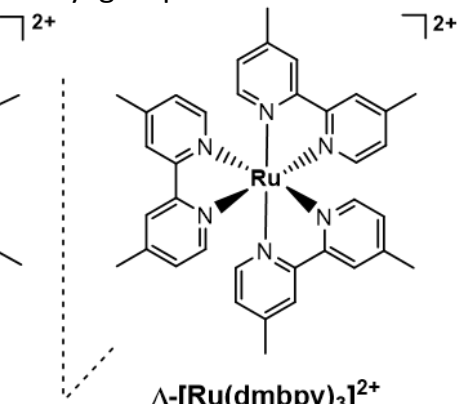

$\Delta-\left[\operatorname{Ru}(\mathrm{dmbpy})_{3}\right]^{2+}$

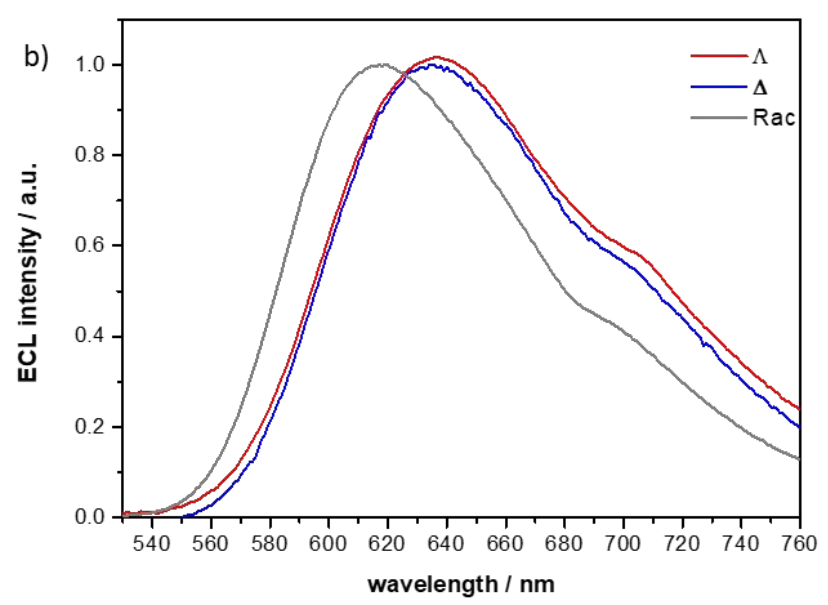

Fig. 1 a) Molecular structures of the two enantiomers $\Lambda$ - and $\Delta-\left[R u(d m b p y)_{3}\right]^{2+}$. b) $E C L$ spectra of $\Lambda$ - and $\Delta-\left[\mathrm{Ru}(\mathrm{dmbpy})_{3}\right]^{2+}$ and of the racemic $\left[\mathrm{Ru}(\mathrm{bpy})_{3}\right]^{2+}$ mixture. ECL spectra were recorded in PBS ( $\mathrm{pH}$ 7.4) containing $1 \mathrm{mM}$ of the dye and $0.2 \mathrm{M}$ TPrA. A potential of $1.5 \mathrm{~V}$ was applied to the glassy carbon working electrode for $30 \mathrm{~s}$.

$\left[\mathrm{Ru}(\mathrm{dmbpy})_{3}\right]^{2+}$ show a typical broad metal-to-ligand chargetransfer (MLCT) emission band peaking at $\lambda_{\max }=625 \mathrm{~nm}$ (Fig. S3). It is red-shifted in comparison to the racemic $\left[\mathrm{Ru}(\mathrm{bpy})_{3}\right]^{2+}\left(\lambda_{\max }=612 \mathrm{~nm}\right) .{ }^{34}$ This shift is in accordance with the lower oxidation potential value measured by cyclic voltammetry for the enantiomers.

$\mathrm{ECL}$ emission was generated by using the classic and very efficient TPrA coreactant. ${ }^{6}$ Identical ECL spectra with a maximum pointing at $\lambda_{\max }=637 \mathrm{~nm}$ were recorded for both enantiomers (Fig. 1b). Such a small red-shift ( $12 \mathrm{~nm}$ ) between $\mathrm{ECL}$ and PL spectra is common in ECL and caused by the inner filter effect due to the high concentration of dye used in $\mathrm{ECL}$ ( $\mathrm{mM}$ range) in comparison to $\mathrm{PL}$ ( $\mu \mathrm{M}$ range) experiments. ${ }^{36}$ Indeed, the same difference between $\mathrm{PL}$ and $\mathrm{ECL}$ bands was observed for the racemic $\left[\mathrm{Ru}(\mathrm{bpy})_{3}\right]^{2+}$. Whatever, it indicates that the same MLCT excited state was reached by photoexcitation (i.e. $\mathrm{PL}$ ) and by electro-excitation (i.e. $\mathrm{ECL}$ ) for the $\Delta$ and $\Lambda$ - $\left[\mathrm{Ru}(\mathrm{dmbpy})_{3}\right]^{2+}$ complexes.

The CP-PL and CP-ECL measurements were performed on the enantiopure $\Delta$ - and $\Lambda$-[Ru(dmbpy $\left.)_{3}\right]^{2+}$ complexes and on the racemic $\left[\mathrm{Ru}(\mathrm{bpy})_{3}\right]^{2+}$. CP-PL measurements were carried out in PBS under $365 \mathrm{~nm}$ illumination. The corresponding CP-PL spectra are plotted in Fig. 2 in the spectral range of the MLCT band. A clear positive CP-PL band was evidenced for $\Lambda$ $\left[\mathrm{Ru}(\mathrm{dmbpy})_{3}\right]^{2+}$, whereas a negative signal was observed for 
$\Delta$-[Ru(dmbpy $\left.)_{3}\right]^{2+}$. Indeed, both enantiomers gave mirror image CP-PL spectra. As a control experiment, the CP-PL signal of racemic $\left[\mathrm{Ru}(\mathrm{bpy})_{3}\right]^{2+}$ was recorded in the same experimental conditions. In this case, no significant circular polarization was

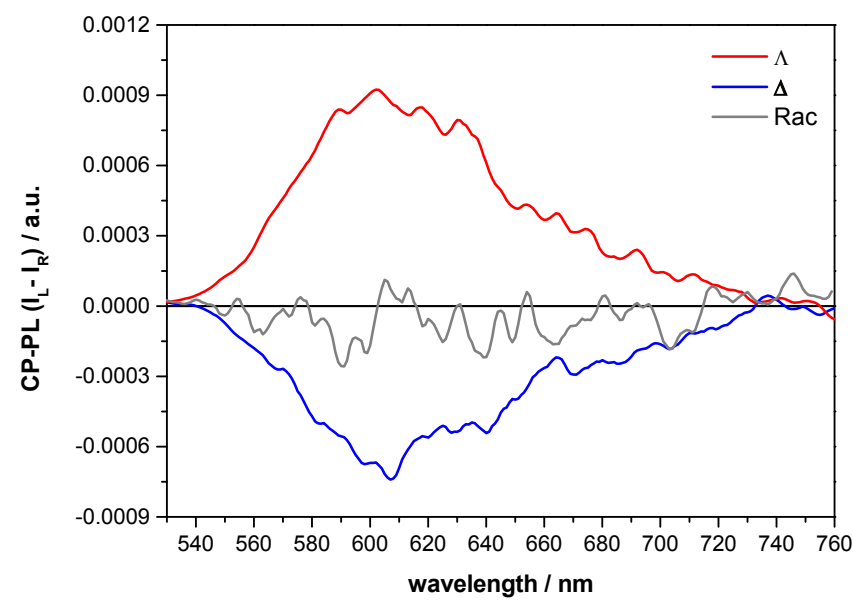

Fig. $2 \mathrm{CP}-\mathrm{PL}$ of both enantiomers of $\left[\mathrm{Ru}(\mathrm{dmbpy})_{3}\right]^{2+}$ and of the racemic mixture of $\left[\mathrm{Ru}(\mathrm{bpy})_{3}\right]^{2+}$.

observed (Fig. 2). The estimated $g_{P L}$ values are $+7 \times 10^{-4}$ and -7 $\times 10^{-4}$ for the $\Lambda$ - and $\Delta$-[Ru(dmbpy $\left.)_{3}\right]^{2+}$ enantiomers, respectively. Indeed, these values are consistent in sign and magnitude with previous CP-PL works on similar ruthenium complexes. ${ }^{21,37}$

Considering the low values of $g_{P L}$ for the ruthenium complexes, we optimized the experimental protocol in order to record the $C P-E C L$ signals, even if the ECL emission of the tandem $\left[\mathrm{Ru}(\mathrm{dmbpy})_{3}\right]^{2+} / \operatorname{TPr} \mathrm{A}$ system was strong. This is simply due to the extremely low fraction of the emission showing a net preferential circular polarization for each enantiomer. For a series of incremental wavelength, several on-off ECL cycles (30 sec on, $20 \mathrm{sec}$ off) were imposed sequentially 6 times. During this time duration, both luminescence $\left(I_{\mathrm{ECL}}\right)$ and $\Delta I=\left(I_{L}-I_{R}\right)$ signals were acquired. The average ratios $2 \Delta l / I_{\mathrm{ECL}}\left(g_{E C L}\right)$ were calculated in the stability region of the $E C L$ on-cycles and are reported in Fig. 3. The standard deviations were calculated over the different on-off cycles and are reported in the same figure. One can observe that the $g_{E C L}$ values (Fig. 3, dots) are comparable to the $g_{P L}$ ones (Fig. 3, plain lines The $g_{E C L}$ factors recorded for the two enantiomers are similar in value but opposite in sign. $\Lambda$ - $\left[\mathrm{Ru}(\mathrm{dmbpy})_{3}\right]^{2+}$ gave a positive $\mathrm{CP}-\mathrm{ECL}$ signal, which is coherent with the positive CP-PL. The same behavior (but with negative sign) was observed for $\Delta$-[Ru(dmbpy) $\left.)_{3}\right]^{2+}$. Moreover, $g_{E C L}$ and $g_{P L}$ follows a similar but mirror image trend for $\Lambda$ - and $\Delta$-[Ru(dmbpy $\left.)_{3}\right]^{2+}$, respectively (Fig. 3 ). Such trend is in line with previous report. ${ }^{37}$ By contrast, as expected, the dissymmetry factors $g_{E C L}$ and $g_{P L}$ of the racemic mixture are erratic and not significantly different from the noise. In brief, all these figures show that we can discriminate without ambiguity the CP-ECL signals of both enantiomers. In other words, we demonstrated that the combination of CP-PL and ECL (i.e. CP$E C L)$ is able to achieve the chiroptical detection of the $\left[\mathrm{Ru}(\mathrm{dmbpy})_{3}\right]^{2+}$ complexes.
In conclusion, the selective detection of the two enantiomers of a model $\left[\mathrm{Ru}(\mathrm{bpy})_{3}\right]^{2+}$-based dye is successfully realized by combining electrochemiluminescence (ECL) and circularly polarized photoluminescence $(\mathrm{CP}-\mathrm{PL})$. The resulting $\mathrm{CP}-\mathrm{ECL}$ signal associated with $\Lambda$-[Ru(dmbpy $\left.)_{3}\right]^{2+}$ is positive, whereas it

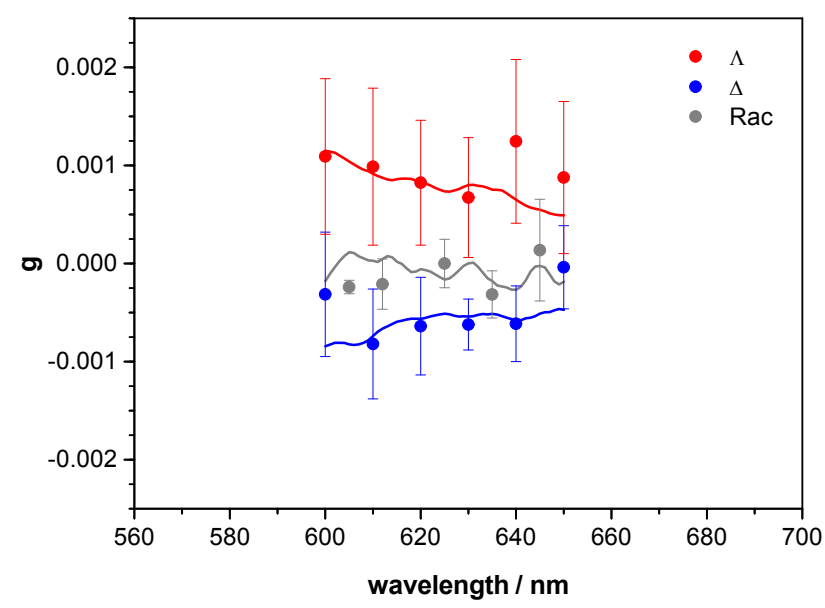

Fig. 3 Comparison between $g_{E C L}$ (dots) and $g_{P L}$ (plain lines) of both enantiomers of $\left[\mathrm{Ru}(\mathrm{dmbpy})_{3}\right]^{2+}$ and of the racemic mixture of $\left[\mathrm{Ru}(\mathrm{bpy})_{3}\right]^{2+}$. The error bars represent one standard deviation and are calculated over 6 on-off cycles for each point.

is negative for $\Delta-\left[R u(d m b p y)_{3}\right]^{2+}$. This is fully coherent with the CP-PL measurements. Moreover, the $g_{E C L}$ values, which is about $\pm 7 \times 10^{-4}$ for the two enantiomers is similar to $g_{P L}$. The reported enantioselective approach herein demonstrated with this classic ECL system broadens significantly the potentialities of $\mathrm{ECL}$ in analytical sciences, paving the way to unprecedented CPECL based (bio)assays and microscopy, useful for chiralrecognition of analytes of biological interest.

\section{Conflicts of interest}

There are no conflicts to declare.

\section{Acknowledgements}

SV thanks the Agence Nationale de la Recherche (Neocastip ANR-15-CE09-0015-03) for financial support. LB acknowledges the Centre National de la Recherche Scientifique (CNRS) for funding $a$ visit to the University of Pisa (Program Emergence@International 2019). LA, FZ and LDB thank the PRIN 20172 M3K5N for financial support. FZ, SG and JL thank the University of Geneva and the Swiss National Science Foundation for financial support (SNF 200020-172497 and 200020-184843).

\section{Notes and references}

‡ Enantiomerically pure $\left[\mathrm{Ru}(\mathrm{dmbpy})_{3}\right] \mathrm{Cl}_{2}$ salts have been previously characterized. ${ }^{28}$

1 A. J. Bard, Electrogenerated Chemiluminescence, M. Dekker, New-York, 2004.

2 N. Sojic, Analytical Electrogenerated Chemiluminescence: From 
Fundamentals to Bioassays, Royal Society of Chemistry (RSC) Publishing, 2020.

3 Z. Liu, W. Qi and G. Xu, Chem. Soc. Rev., 2015, 44, 3117-3142.

4 M. Hesari and Z. Ding, J. Electrochem. Soc., 2016, 163, H3116H3131.

5 W. Miao, J.-P. Choi and A. J. Bard, J. Am. Chem. Soc., 2002, 124, 14478-14485.

6 Y. Yuan, S. Han, L. Hu, S. Parveen and G. Xu, Electrochim. Acta, 2012, 82, 484-492.

7 M. Sentic, M. Milutinovic, F. Kanoufi, D. Manojlovic, S. Arbault and N. Sojic, Chem. Sci., 2014, 5, 2568-2572.

8 X. Zhou, D. Zhu, Y. Liao, W. Liu, H. Liu, Z. Ma and D. Xing, Nat. Protocols, 2014, 9, 1146-1159.

9 F. Deiss, C. N. LaFratta, M. Symer, T. M. Blicharz, N. Sojic and D. R. Walt, J. Am. Chem. Soc., 2009, 131, 6088-6089.

10 L. Chen, D. J. Hayne, E. H. Doeven, J. Agugiaro, D. J. D. Wilson, L. C. Henderson, T. U. Connell, Y. H. Nai, R. Alexander, S. Carrara, C. F. Hogan, P. S. Donnelly and P. S. Francis, Chem. Sci., 2019, 10, 8654-8667.

11 K. N. Swanick, S. Ladouceur, E. Zysman-Colman and Z. Ding, Angew. Chem. Int. Ed., 2012, 51, 11079-11082.

12 R. Carr, N. H. Evans and D. Parker, Chem. Soc. Rev., 2012, 41, 7673-7686.

13 J. Yuasa, T. Ohno, H. Tsumatori, R. Shiba, H. Kamikubo, M. Kataoka, Y. Hasegawa and T. Kawai, Chem. Commun., 2013, 49, 4604-4606.

14 M. Leonzio, A. Melchior, G. Faura, M. Tolazzi, M. Bettinelli, F. Zinna, L. Arrico, L. Di Bari and F. Piccinelli, New J. Chem., 2018, 42, 7931-7939.

15 M. Górecki, F. Zinna, T. Biver and L. Di Bari, J. Pharm. Biomed. Anal., 2017, 144, 6-11.

16 F. Zinna and L. Di Bari, Chirality, 2015, 27, 1-13.

17 J.-R. Jiménez, B. Doistau, C. M. Cruz, C. Besnard, J. M. Cuerva, A. G. Campaña and C. Piguet, J. Am. Chem. Soc., 2019, 141, 1324413252.

18 C. Dee, F. Zinna, W. R. Kitzmann, G. Pescitelli, K. Heinze, L. Di Bari and M. Seitz, Chem. Commun., 2019, 55, 13078-13081.

19 E. M. Sánchez-Carnerero, A. R. Agarrabeitia, F. Moreno, B. L. Maroto, G. Muller, M. J. Ortiz and S. de la Moya, Chem. Eur. J., 2015, 21, 13488-13500.

20 F. Zinna, S. Voci, L. Arrico, E. Brun, A. Homberg, L. Bouffier, T. Funaioli, J. Lacour, N. Sojic and L. Di Bari, Angew. Chem. Int. Ed., 2019, 58, 6952-6956.

21 P. M. L. Blok, P. S. Cartwright, H. P. J. M. Dekkers and R. D. Gillard, J. Chem. Soc., Chem. Commun., 1987, 1232-1233.

22 V. Balzani, A. Juris and M. Venturi, Chem. Rev., 1996, 96, 759833.

23 C. Paola, B. Giacomo and B. Vincenzo, Angew. Chem. Int. Ed., 2009, 48, 8516-8518.

24 L. Gong, M. Wenzel and E. Meggers, Acc. Chem. Res., 2013, 46, 2635-2644.

25 M. Oppermann, B. Bauer, T. Rossi, F. Zinna, J. Helbing, J. Lacour and M. Chergui, Optica, 2019, 6, 56-60.

26 J. Lacour and D. Moraleda, Chem. Commun., 2009, 7073-7089.

27 J. Lacour, C. Ginglinger, C. Grivet and G. Bernardinelli, Angew. Chem. Int. Ed. Engl., 1997, 36, 608-609.

28 J. Lacour, C. Goujon-Ginglinger, S. Torche-Haldimann and J. J. Jodry, Angew. Chem. Int. Ed., 2000, 39, 3695-3697.

29 J. Lacour, S. Torche-Haldimann, J. J. Jodry, C. Ginglinger and F. Favarger, Chem. Commun., 1998, 1733-1734.

30 J. J. Jodry, R. Frantz and J. Lacour, Inorg. Chem., 2004, 43, 33293331.
31 M. Oppermann, B. Bauer, T. Rossi, F. Zinna, J. Helbing, J. Lacour and M. Chergui, Optica, 2018, 6, 56-59.

32 T. J. Rutherford, P. A. Pellegrini, J. Aldrich-Wright, P. C. Junk and F. R. Keene, Eur. J. Inorg. Chem., 1998, 1998, 1677-1688.

33 A. J. McCaffery, S. F. Mason and B. J. Norman, J. Chem. Soc. A, 1969, 1428-1441.

34 F. Bolleta, M. Ciano, V. Balzani and N. Serpone, Inorg. Chim. Acta, 1982, 62, 207-213.

35 F. Kanoufi and A. J. Bard, J. Phys. Chem. B, 1999, 103, 1046910480.

36 M. Shen, X.-H. Zhu and A. J. Bard, J. Am. Chem. Soc., 2013, 135, 8868-8873.

37 A. Gafni and I. Z. Steinberg, Isr. J. Chem., 1976, 15, 102-105. 